\title{
Surface Functionalization of 2D MXenes: Trends in Distribution, Composition, and Electronic Properties
}

\author{
Rina Ibragimova, Paul Erhart, Patrick Rinke, and Hannu-Pekka Komsa* \\ Cite This: J. Phys. Chem. Lett. 2021, 12, 2377-2384 \\ Read Online
}

ABSTRACT: Using a multiscale computational scheme, we study the trends in distribution and composition of the surface functional groups $-\mathrm{O},-\mathrm{OH}$, and $-\mathrm{F}$ on two-dimensional (2D) transition metal carbides and nitrides (MXenes). We consider $\mathrm{Ti}_{2} \mathrm{~N}, \mathrm{Ti}_{4} \mathrm{~N}_{3}, \mathrm{Nb}_{2} \mathrm{C}, \mathrm{Nb}_{4} \mathrm{C}_{3}, \mathrm{Ti}_{2} \mathrm{C}$, and $\mathrm{Ti}_{3} \mathrm{C}_{2}$ to explore MXenes with different chemistry and different number of atomic layers. Using a combination of cluster expansion, Monte Carlo, and density functional theory methods, we study the distribution and composition of functional groups at experimentally relevant conditions. We show that mixtures of functional groups are favorable on all studied MXene surfaces. The distribution of functional groups appears to be largely independent of the type of metal, carbon, or nitrogen species and/or number of atomic layers in the MXene. We further show that some properties (e.g., the work function) strongly depend on the surface composition, while others, for example, the electric conductivity, exhibit only a weak dependence.

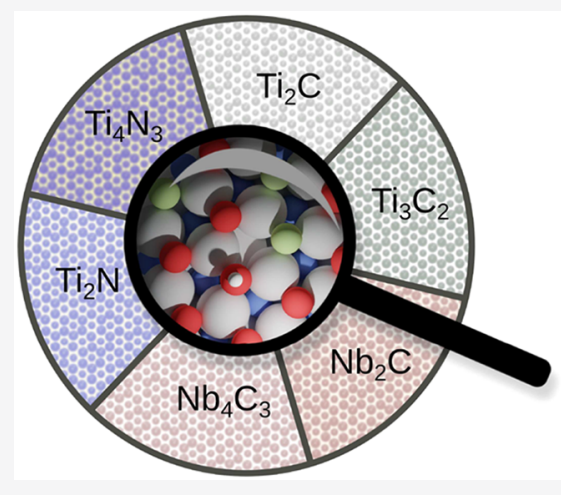

$\mathrm{M}$ Xenes are 2D materials with the general composition $\mathrm{M}_{n+1} \mathrm{X}_{n}$, where $\mathrm{M}$ is a transition metal and $\mathrm{X}$ is carbon or nitrogen. ${ }^{1,2}$ MXenes include materials with different $M$ and $\mathrm{X}$ combinations, ${ }^{1-4}$ ordered materials with different metal combinations in outer and inner layer $\mathrm{M}_{2}^{\prime} \mathrm{M}^{\prime \prime} \mathrm{X}_{2}{ }^{5}$ and phases with ordered divacancies in the structure $\mathrm{M}_{1.33} \mathrm{X}$ called $\mathrm{i}$ MXenes. ${ }^{6}$ Herein, we focus on MXenes with one $M$ element in the structure, the combination of element $M$ and $X$ and different numbers of atomic layers: $\mathrm{M}_{2} \mathrm{X},{ }^{1,2} \mathrm{M}_{3} \mathrm{X}_{2}, \mathrm{M}_{4} \mathrm{X}_{3}{ }^{7,8}$ and $\mathrm{M}_{5} \mathrm{X}_{4}{ }^{9}{ }^{9}$ They possess extraordinary electronic, mechanical, optical, thermal, and catalytic properties. ${ }^{10-17}$ During wetetching synthesis of MXenes, ${ }^{1,4}$ their surfaces adsorb functional groups such as $-\mathrm{O},-\mathrm{OH}$, and $-\mathrm{F} .{ }^{18-24}$ Even though a variety of MXene properties such as work function, hydrophilic behavior, and catalytic activity are ascribed to the surface functionalization, ${ }^{1,25-27}$ the structure and composition of the functionalized surfaces remain unknown for most MXenes.

To date, several experimental studies have reported significant variations in the surface composition of freshly prepared MXenes. ${ }^{7,28-37}$ However, the experimental characterization of MXene surfaces is challenging because (i) the surface contains light elements such as $\mathrm{H}, \mathrm{O}$, and F; (ii) the surface is often contaminated with water and precursors remaining after etching, and (iii) variations in the experimental conditions aggravate systematic studies. For example, the XPS analysis of Halim et al. ${ }^{7}$ reveals that $\mathrm{Ti}_{3} \mathrm{C}_{2}, \mathrm{Ti}_{2} \mathrm{C}, \mathrm{Ti}_{3} \mathrm{CN}, \mathrm{Nb}_{2} \mathrm{C}$, and $\mathrm{Nb}_{4} \mathrm{C}_{3}$ all exhibit a mixture of $\mathrm{O} / \mathrm{OH} / \mathrm{F}$ when etched with $\mathrm{HF}$, although with slightly different compositions. Conversely, $\mathrm{Ti}_{2} \mathrm{~N}$ and $\mathrm{Ti}_{4} \mathrm{~N}_{3}$ obtained from molten-salt etching ${ }^{28-30}$ accommodate only a mixture of $\mathrm{O}$ and $\mathrm{OH}$, and no F. It is not known whether the absence of $F$ is triggered by the material itself or is a result of the synthesis method. To date, no clear picture has emerged on what factors determine the composition and distribution of surface functional groups.

First-principles calculations complement experimental studies and provide atomistic insight into the surface functionalization. However, to date the majority of theoretical studies considered only pure terminations of $\mathrm{O}, \mathrm{F}$, or $\mathrm{OH},{ }^{1,25,38-55}$ and there are only a few studies involving mixtures of functional groups. ${ }^{56-58}$ To address mixed functionalization, we recently developed a multiscale computational scheme to find the equilibrium composition of statistically averaged distributions of $-\mathrm{O},-\mathrm{OH}$, and $-\mathrm{F}$ functional groups on MXene surfaces, also taking into account the interactions with a solvent. $^{59}$ The scheme was employed to study Ti-based carbides for certain experimental conditions characterized by the $\mathrm{pH}$ value, the open-circuit potential (OCP), and the growth temperature. However, a systematic study of surface functionalization of MXenes is still missing.

In this Letter, we remedy this situation and provide a systematic, atomic-scale analysis of surface functionalization for titanium $(\mathrm{Ti})$ and niobium $(\mathrm{Nb})$ carbides and nitrides of varying thickness. The diversity of MXenes provides a large design space, which we narrow down here by exploring three

Received: December 17, 2020

Accepted: February 25, 2021

Published: March 3, 2021 
of its dimensions: the type of metal $(\mathrm{M})$, the type of $\mathrm{X}$ element, and the number of atomic layers $n$. Moreover, we select materials that have already been synthesized to be able to compare to experimental data. Furthermore, we exclude elements that give rise to magnetic properties and/or where strong correlations may be expected. On the basis of these criteria, we have selected the following MXenes: $\mathrm{Ti}_{2} \mathrm{~N}, \mathrm{Ti}_{4} \mathrm{~N}_{3}$, $\mathrm{Nb}_{2} \mathrm{C}, \mathrm{Nb}_{4} \mathrm{C}_{3}, \mathrm{Ti}_{2} \mathrm{C}$, and $\mathrm{Ti}_{3} \mathrm{C}_{2}$ for our study (Figure $1 \mathrm{a}$ ).

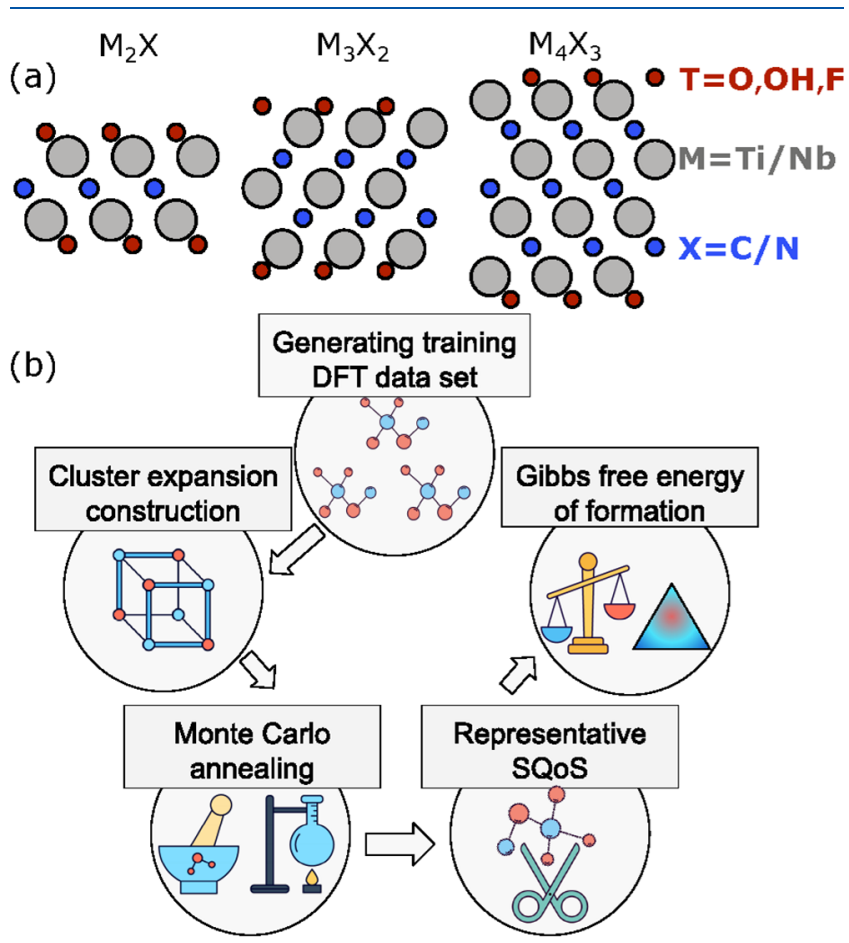

Figure 1. (a) Side-view structures of the considered MXenes of different thickness: $M_{2} X, M_{3} X_{2}$, and $M_{4} X_{3}$. (b) Schematic of our multiscale computational scheme.

Our multiscale approach is schematically depicted in Figure 1b. First, we generate a set of three-component (F, O, and $\mathrm{OH})$ reference structures for each considered MXene. For these structures, we perform density functional theory (DFT) calculations using the VASP code. ${ }^{60}$ Next, we construct a cluster expansion (CE) Hamiltonian for each MXene using the icet code. ${ }^{61}$ The CE is fitted to the DFT energies for the reference structures using Bayesian linear regression via the automatic relevance detection (ARD) scheme ${ }^{62}$ (see fit quality in Figure S1b). We include pair clusters up to the fourthnearest neighbors and triplet clusters up to first-nearest neighbors in the $\mathrm{CE}$ (Figures S1a and S2). We then use Monte Carlo (MC) simulations to sample the configurational space and to compute the configurational free energies for different surface terminations (see the Supporting Information for simulation details). ${ }^{63}$ In this way, we obtain the equilibrium distribution of functional groups on different MXenes. To further analyze the properties of thermodynamically averaged structures, we use the special-quasiordered-structures method $(\mathrm{SQoS})^{64,65}$ and generate representative $4 \times 4 \times 1$ supercells for 12 fixed concentrations of functional groups. The generated structures exhibit a distribution of functional groups that closely mimic those observed in the larger supercells sampled during the MC simulations. Finally, we calculate the Gibbs free energy of formation for the generated structures in solution over the whole range of composition of the functional groups, carefully accounting for the role of experimental factors, such as temperature, $\mathrm{pH}$, and open-circuit potential.

Distribution of Functional Groups. We start with the analysis of functional group distributions obtained from the MC simulations, which were carried out for 12 structures with compositions $\mathrm{M}_{n+1} \mathrm{X}_{n}-\left(\mathrm{O}_{x} \mathrm{OH}_{z} \mathrm{~F}_{1-x-z}\right)_{2}$, where $x$ and $z$ vary from 0 to 1 in steps of 0.25 . Radial distribution functions for $\mathrm{O}-\mathrm{OH}$ pairs of all MXenes at $\left(\mathrm{O}_{0.5} \mathrm{OH}_{0.5}\right)_{2}$ composition are shown in Figure 2a. The radial distribution functions are almost identical for all six systems, which indicates that the distribution of functional groups does not depend on the type of MXene. Therefore, in the following we show only the distributions for $\mathrm{Ti}_{2} \mathrm{~N}$.

The surface distribution for excess $\mathrm{F}\left(\mathrm{Ti}_{2} \mathrm{~N}-\right.$ $\left(\mathrm{F}_{0.5} \mathrm{O}_{0.25} \mathrm{OH}_{0.25}\right)_{2}$ in Figure $\left.2 \mathrm{~b}, \mathrm{c}\right)$ shows that fluorine atoms are arranged in strips with a thickness of one or two atomic rows. The spaces between F-strips are mainly filled with an ordered distribution of alternating $\mathrm{O}$ and $\mathrm{OH}$ groups. Likewise, excess $\mathrm{O}\left[\left(\mathrm{F}_{0.25} \mathrm{O}_{0.5} \mathrm{OH}_{0.25}\right)_{2}\right.$ in Figure 2d] leads to the formation of oxygen-containing strips. $\mathrm{F}$ and $\mathrm{OH}$ alternate in the remaining space, although with more $\mathrm{F}-\mathrm{F}$ and $\mathrm{OH}-\mathrm{OH}$ pairs than for excess $\mathrm{F}$. The binary structure with $50 \%$ of $\mathrm{O}$ and $\mathrm{OH}$ is depicted in Figure 2e and exhibits alternating $\mathrm{O}$ and $\mathrm{OH}$ strips. In the case of $\left(\mathrm{O}_{0.75} \mathrm{OH}_{0.25}\right)_{2}$ in Figure $2 \mathrm{f}$, the $\mathrm{OH}$ groups are evenly distributed within the $\mathrm{O}$ groups.

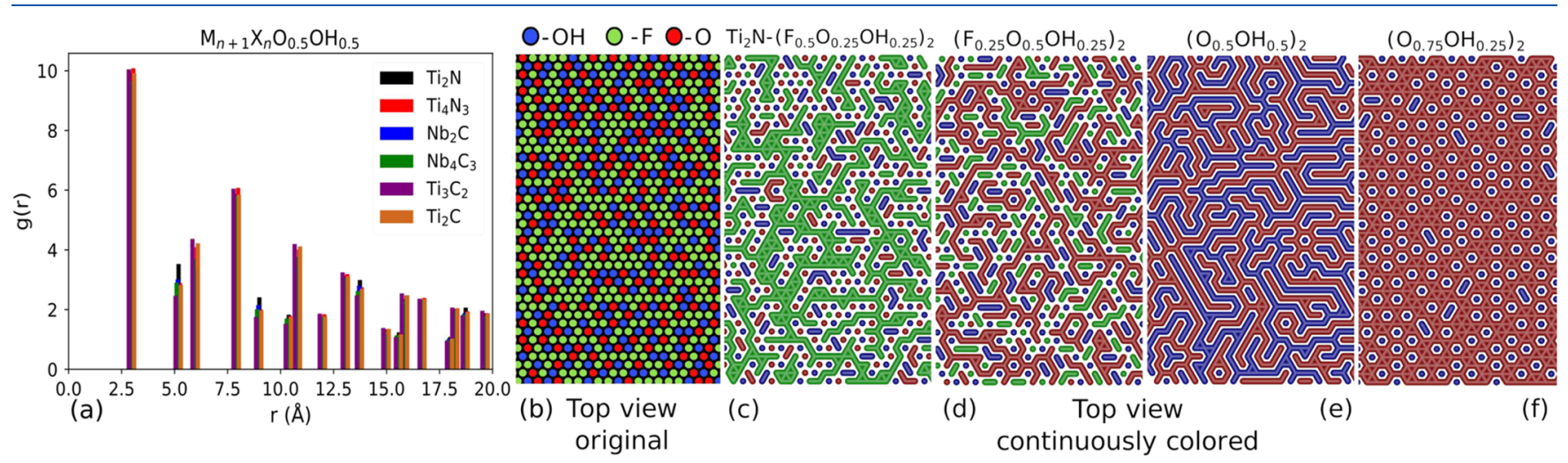

Figure 2. (a) $\mathrm{O}-\mathrm{OH}$ radial distribution function for all systems and surface structures of (b) $\mathrm{Ti}_{2} \mathrm{~N}\left(\mathrm{~F}_{0.5} \mathrm{O}_{0.25} \mathrm{OH}_{0.25}\right)_{2}$ (original schematics of surface coverage), (c) $\mathrm{Ti}_{2} \mathrm{~N}\left(\mathrm{~F}_{0.5} \mathrm{O}_{0.25} \mathrm{OH}_{0.25}\right)_{2}$, (d) $\mathrm{Ti}_{2} \mathrm{~N}\left(\mathrm{~F}_{0.25} \mathrm{O}_{0.5} \mathrm{OH}_{0.25}\right)_{2}$, (e) $\mathrm{Ti}_{2} \mathrm{~N}\left(\mathrm{O}_{0.5} \mathrm{OH}_{0.5}\right)_{2}$, (f) $\mathrm{Ti}_{2} \mathrm{~N}\left(\mathrm{O}_{0.75} \mathrm{OH}_{0.25}\right)_{2}$. In panels $\mathrm{c}-\mathrm{f}$ the nearest neighbors of the same type are connected to highlight the ordering. 

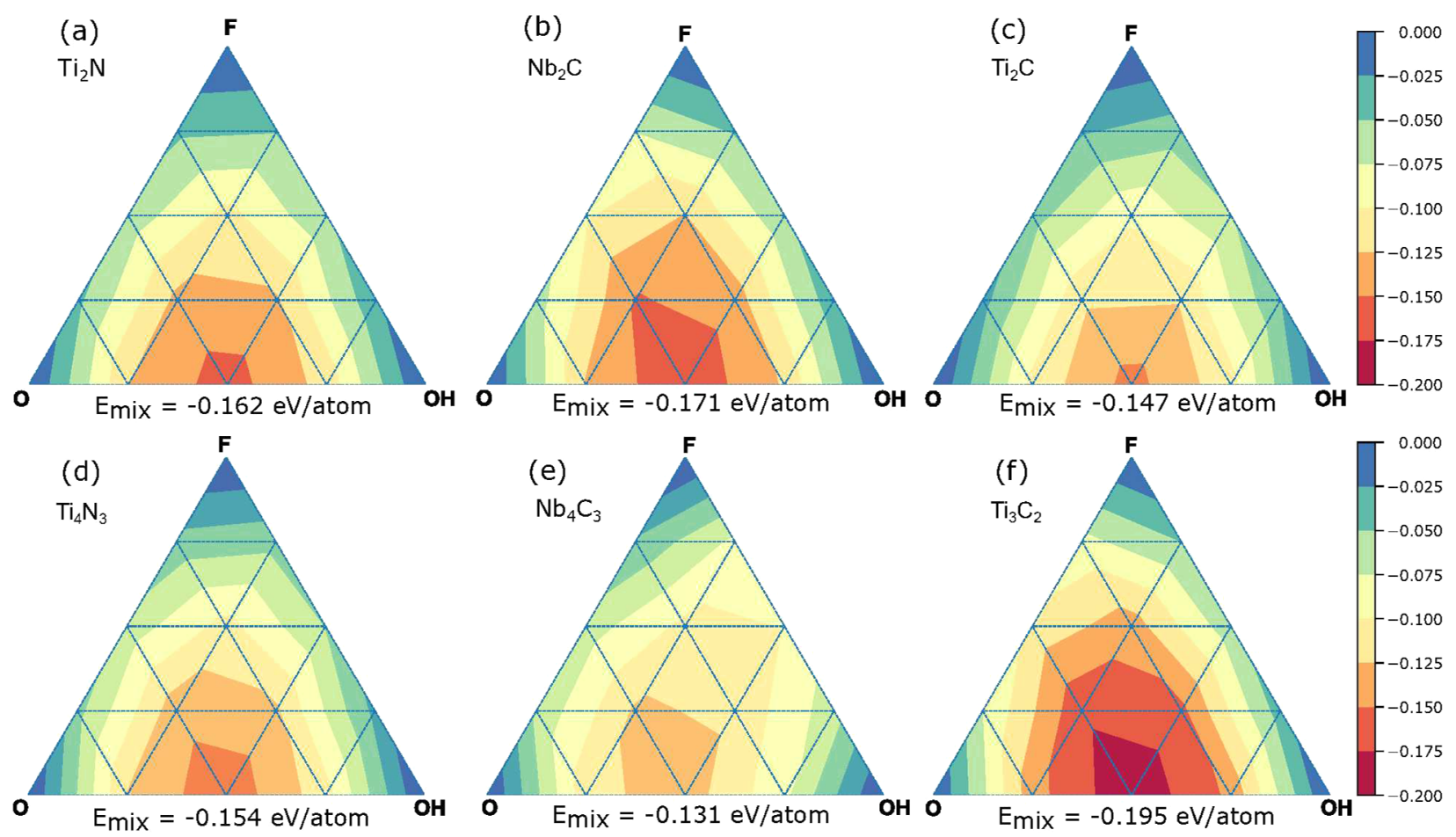

Figure 3. Mixing energy (in eV per MXene unit cell; each unit cell contains two surface sites) of (a) $\mathrm{Ti}_{2} \mathrm{~N},(\mathrm{~b}) \mathrm{Nb}_{2} \mathrm{C},(\mathrm{c}) \mathrm{Ti}_{2} \mathrm{C},(\mathrm{d}) \mathrm{Ti}_{4} \mathrm{~N}_{3},(\mathrm{e})$ $\mathrm{Nb}_{4} \mathrm{C}_{3}$, and (f) $\mathrm{Ti}_{3} \mathrm{C}_{2}$ as a function of the concentrations of $-\mathrm{O},-\mathrm{F}$, and $-\mathrm{OH}$.

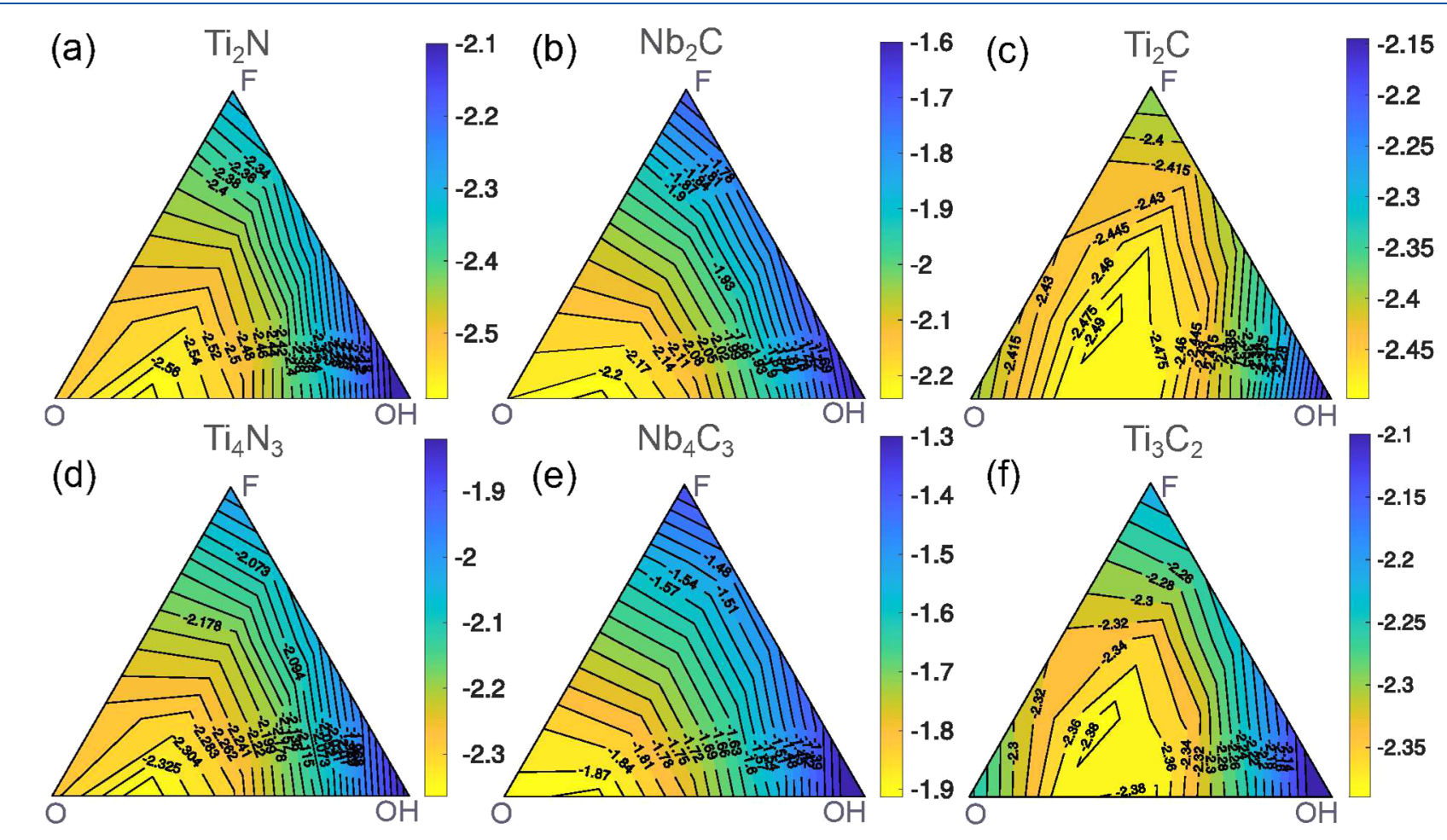

Figure 4. Gibbs free energy of formation for (a) $\mathrm{Ti}_{2} \mathrm{~N}$, (b) $\mathrm{Nb}_{2} \mathrm{C}$, (c) $\mathrm{Ti}_{2} \mathrm{C}$, (d) $\mathrm{Ti}_{4} \mathrm{~N}_{3}$, (e) $\mathrm{Nb}_{4} \mathrm{C}_{3}$, and (f) $\mathrm{Ti}_{3} \mathrm{C}_{2}$. The diagrams are plotted for $\mathrm{SHE}$ conditions $\left(\mathrm{pH}=0 ; U-U_{\mathrm{SHE}}=0 \mathrm{~V}\right)$.

The strip patterns were observed for all studied systems independent of the composition in terms of metal species (M) and carbon or nitrogen $(\mathrm{X})$ as well as the number of atomic layers $(n)$. Overall, the functional groups clearly mix and do not exhibit phase separation or agglomeration. The mixing happens on the atomic scale; that is, the connected features are atomically thin. We attribute the emergence of strip patterns to the triangular lattice of MXenes. In $\mathrm{O}-\mathrm{OH}$ binaries, maximizing the number of $\mathrm{O}-\mathrm{OH}$ bonds leads to a strong geometrical frustration in all MXene systems that usually manifests itself in the formation of strip patterns as observed here. The geometrical frustration usually gives rise to a 

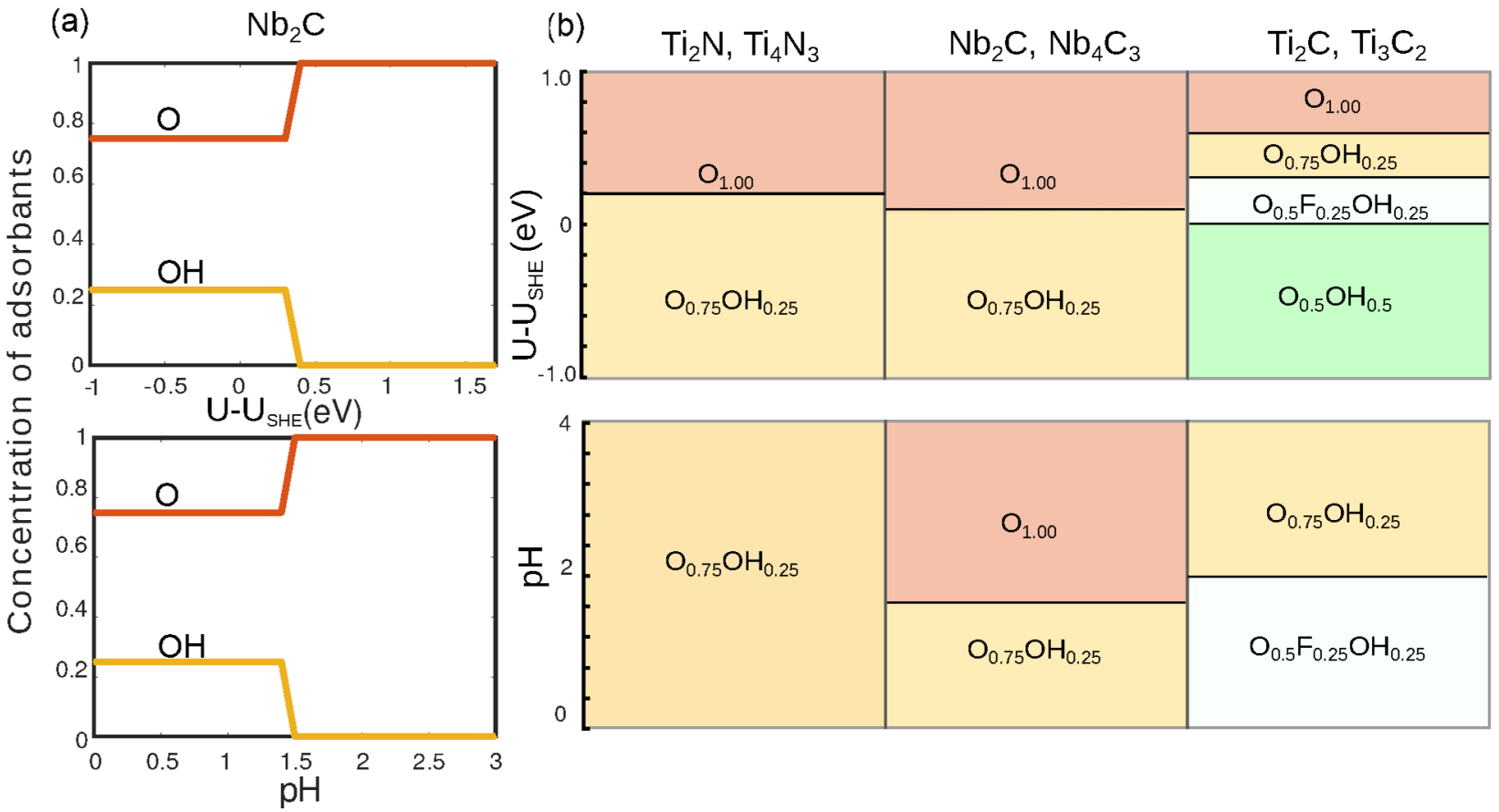

Figure 5. (a) Composition with the lowest energy for $\mathrm{Nb}_{2} \mathrm{C}$ dependent on the open-circuit potential (top panel) and the $\mathrm{pH}$ (bottom panel). (b) Summary of stable compositions for all systems as a function of the open-circuit potential (at pH 0 ; top panel) and $\mathrm{pH}\left(\right.$ at $U-U_{\mathrm{SHE}}=0 \mathrm{~V}$; bottom panel).

manifold of ground states rather than a single stable ground state. $^{66}$ As a result, the system will be sensitive to slight perturbations, meaning that slight variations of the external conditions can easily lead to changes in the surface group distribution.

The ternary diagrams of the mixing energy are depicted in Figure 3, which shows the mixing energy as a function of the concentrations of $-\mathrm{F},-\mathrm{O}$, and $-\mathrm{OH}$ functional groups for the considered MXenes. We observe a pronounced minimum for binary compositions with $50 \% \mathrm{O}$ and $50 \% \mathrm{OH}\left(\mathrm{O}_{0.5} \mathrm{OH}_{0.5}\right)$ for all systems. The absolute mixing energies, however, vary with no clearly discernible trend. $\mathrm{Nb}_{4} \mathrm{C}_{3}$ has the smallest mixing energy of $-0.13 \mathrm{eV}$ and $\mathrm{Ti}_{3} \mathrm{C}_{2}$ the largest $(-0.2 \mathrm{eV})$. With an increasing number of atomic layers, the absolute values of the mixing energy decrease for $\mathrm{Ti}_{4} \mathrm{~N}_{3}$ and $\mathrm{Nb}_{4} \mathrm{C}_{3}$ but not for $\mathrm{Ti}_{3} \mathrm{C}_{2}$.

The strong preference toward mixing in our $\mathrm{CE}$ indicates that the surface functionalization is primarily determined by interactions between functional groups. While changes in the Fermi-level position could change the bond strength between functional groups and the substrate, this would lead to similar mixing energies for all structural configurations with the same composition, clearly contradicting our CE results. Moreover, if the bonding energy depended on the Fermi-level position, the mixing energy curves were unlikely to look so similar because in different MXenes the Fermi level falls into different regions of the metal d-band. The similarity of the mixing energy diagrams (Figure 3) points toward interactions that are inherent to the functional groups. Because the distance between the functional groups is too large for direct chemical bonding, the functional group distribution is likely dictated by electrostatic interactions. In the case of differently charged functional groups, the electrostatic energy of a mixed system is always lower than for a segregated system. To this end, we evaluated the charges associated with each atom, using the Bader method. ${ }^{67}$ The average number of electrons that are associated with $\mathrm{O}$ and $\mathrm{OH}$ increases almost linearly with the amount of $\mathrm{OH}$ in the system (Figure S4a,c). This dependence is similar in every studied system, and we found no clear correlation with the maximum mixing energy or substrate chemistry and the number of atomic layers. The charge difference between $\mathrm{O}$ and $\mathrm{OH}$ groups is similar (0.6-0.7 e) in all materials, consistent with the similarity of the distributions of functional groups and the mixing energy diagrams. On the other hand, the charges of $\mathrm{N}$ and $\mathrm{C}$ atoms do depend on the surrounding metallic species, which subsequently changes the charge in the metal atom and thus the filling of the metal dband, as will be seen from the density of states below.

Equilibrium Composition. Next we evaluate the thermodynamic equilibrium composition of surface terminations in $\mathrm{HF}$ solution after the etching by means of Gibbs free energy of formation calculations. We assume that all species are in equilibrium in order to set the chemical potentials for $\mathrm{F}, \mathrm{O}$, and $\mathrm{H}$ and link them to the $\mathrm{pH}$ of the solution as well as to the open-circuit potential and the temperature. Full details of our approach can be found in ref 59 .

Figure 4 shows the ternary diagrams of the Gibbs free energy of formation for mixed surface terminations. The chemical potentials are determined at standard hydrogen electrode (SHE) conditions, where the $\mathrm{pH}$ is equal to 0 , and the electron chemical potential is fixed to the calculated $U_{\mathrm{SHE}}=4.7 \mathrm{eV}$ (see the Supporting Information for calculation details). SHE conditions correspond to $\mathrm{H}_{2}$ molecules splitting into two $\mathrm{H}^{+}$ ions, and we anticipate that the functionalization happens near those conditions because of the high $\mathrm{H}^{+}$content in the solution. For Ti-based nitrides (Figure 4a,d), we find a minimum in the Gibbs free energy at $\mathrm{O}_{0.75} \mathrm{OH}_{0.25}$ composition. The same composition of $\mathrm{O}_{0.75} \mathrm{OH}_{0.25}$ was found for $\mathrm{Nb}$-based carbides (Figure 4b,e). However, for the Ti-based carbides (Figure $4 \mathrm{c}, \mathrm{f}$ ), the minimum occurs at $\mathrm{O}_{0.50} \mathrm{OH}_{0.25} \mathrm{~F}_{0.25}$. In all systems, the number of atomic layers does not affect the 
equilibrium composition. The difference in energy between fully O-terminated and $\mathrm{O}_{0.75} \mathrm{OH}_{0.25}$ configurations (Ti nitrides and $\mathrm{Nb}$ carbides) is rather small $(0.02-0.05 \mathrm{eV})$, indicating that both phases, $\mathrm{O}$ and $\mathrm{O}_{0.75} \mathrm{OH}_{0.25}$, might be accessible during synthesis. We note that the minima of mixing energies were always found at the same composition (Figure 3) for all systems; however, the Gibbs free energy minima are located at different compositions. This difference is caused by the different values of the formation energies of the pure functionalized surfaces. For example, for Nb-based MXenes, a strong preference for the O-terminated surfaces seems to overcome the mixing energy gain.

Figure 5a depicts the surface composition of $\mathrm{Nb}_{2} \mathrm{C}$ as a function of OCP and $\mathrm{pH}$. We also show full composition diagrams for all systems with different $\mathrm{M}$ and $\mathrm{X}$ in Figure $5 \mathrm{~b}$, where we fixed the $\mathrm{pH}$ value to 0 for the variation of the potential and the value of the potential to $0 \mathrm{eV}$ for the $\mathrm{pH}$ variation. Surfaces of Ti-based nitrides have a high $\mathrm{O}$ content (75\%) with $25 \% \mathrm{OH}$ in the whole $\mathrm{pH}$ range. Increasing the potential to $0.2 \mathrm{eV}$ removes the $\mathrm{OH}$ groups and leads to a fully O-terminated surface. For Nb-based carbides, the situation is similar, only that the transition to a fully O-covered surface also happens for $\mathrm{pH}$ variations. Ti-based carbides exhibit the most complex behavior. Upon increasing the potential, the $\mathrm{OH}$ content can be reduced from $50 \%$ to $0 \%$. At slightly positive potentials also $\mathrm{F}$ can be stabilized in the mix. A similar switch from an $\mathrm{O}-\mathrm{OH}$ mixture to a F-containing one is observed for $\mathrm{pH}$ variations around a $\mathrm{pH}$ value of 2.0 . While an increase in $\mathrm{pH}$ can be problematic for etching systems with strong bonds, the applied electrode potential can be tuned ${ }^{68}$ and thus offers a potentially easy way to affect the surface composition.

Comparing our surface phase diagrams depicted in Figure 5 to experiment, we first note that experimental observations on the surface composition show significant scatter. ${ }^{7,28-37} \mathrm{Ti}-$ based carbides are the most studied systems thus far, and experimental findings could be cherry-picked to support almost any computational result. ${ }^{20,27,36,69,70}$ Focusing only on the high accuracy measurement techniques such as neutron scattering and nuclear magnetic resonance spectroscopy, it emerges that Ti-based carbides have the most mixed compositions out of all considered structures. ${ }^{36,70}$ In ref. 71 , the $\mathrm{pH}$ of the solution was varied from -0.9 to 1.4 by keeping the concentration of HF fixed while changing the other components in the solution. However, the resulting $\mathrm{O}, \mathrm{OH}$, and $\mathrm{F}$ compositions were similar in all cases. Both findings are in general agreement with our calculated results.

Etched $\mathrm{Ti}_{2} \mathrm{~N}$ surfaces (in a mixture of potassium fluoride and hydrochloric acid) accommodate all three functional groups albeit with a predominance for $\mathrm{O} .^{35}$ Conversely, molten-salt synthesis functionalizes the surfaces of $\mathrm{Ti}_{2} \mathrm{~N}$ and $\mathrm{Ti}_{4} \mathrm{~N}_{3}$ mostly with $\mathrm{O}$ and $\mathrm{OH},{ }^{29,30}$ despite the presence of $\mathrm{F}$ during etching. While neither of these experiments directly corresponds to the conditions in our simulations, they tend to agree with our results so far that smaller $\mathrm{F}$ concentrations are observed. Contradicting experimental observations are reported for HF-etched Nb-based carbides. Mixtures of $-\mathrm{OH}$ and $-\mathrm{F}$ functional groups were detected in Nb-based MXenes in nuclear magnetic resonance (NMR) spectroscopy, ${ }^{72}$ while another study reported high $\mathrm{O}$ concentrations for HF-etched $\mathrm{Nb}_{2} \mathrm{C}$ and nonstochiometric mixtures of functional groups for $\mathrm{Nb}_{4} \mathrm{C}_{3}{ }^{7}$ In all of these materials, $\mathrm{OH}$ appears to be the minority species, which is in agreement with our results. The presence of $\mathrm{F}$ in the case of $\mathrm{Ti}$ nitrides and $\mathrm{Nb}$ carbides (and lack thereof in our calculations) can arise from kinetic aspects or too low $\mathrm{F}$ chemical potentials in our calculations, whereas in experiments the $\mathrm{F}$ concentration may be higher because the concentration of available species between the sheets may differ from that of the solution.

Composition-Dependent Properties. Next we analyze how the properties of MXenes change with surface functionalization and its composition. For example, previous computational and experimental studies found that the work function of MXenes strongly depends on the composition of the functional groups. $1,26,27,38,58,59$ This dependence was utilized to engineer the work function and band alignment in solar cells by adding MXene layers to perovskites. ${ }^{73}$

We have calculated the work functions over the whole range of $-\mathrm{O},-\mathrm{OH}$, and $-\mathrm{F}$ concentrations for all the considered systems (Figure S5). The work function depends linearly on the concentration of $\mathrm{O}, \mathrm{F}$, and $\mathrm{OH}$. Fully $\mathrm{O}$ - and F-terminated structures have the highest work functions above $5 \mathrm{eV}$, and the values decrease with an increase of $\mathrm{OH}$ content to about $2 \mathrm{eV}$. The results for pure terminations agree with earlier computational results, ${ }^{8,38}$ while the values for the whole range of $\mathrm{O}$, $\mathrm{OH}$, and $\mathrm{F}$ concentrations are reported here for the first time. Previous calculations found that the work functions are governed by the dipoles formed in the functionaliztion layer. ${ }^{38}$ Consistent with that notion, we observe only a small variation of the work function values for different MXenes. The work function of MXenes therefore depends primarily on the functional group composition and little on the $\mathrm{M}$ or $\mathrm{X}$ species.

MXenes are attractive materials because of their high electrical conductivity. For a first assessment of the conductivity, we here inspect the electronic density of states (DOS). We showed previously that the DOS at the Fermi level of Ti-based carbides only weakly depends on the accessible functional group composition. ${ }^{59}$ In Figure 6 we show the total and atom-projected DOSs for $\mathrm{Ti}_{2} \mathrm{~N}$ and $\mathrm{Nb}_{2} \mathrm{C}$ for different $\mathrm{O}$ and $\mathrm{OH}$ concentrations. The DOSs for other calculated systems are shown in Figure S6. F groups are expected to behave similarly to $\mathrm{OH}$ groups, because they both accept one electron. Similar to Ti-based carbides, the Fermi level falls inside the metal d-band independent of functionalization, and the same is true for the studied systems regardless of the type of $\mathrm{M}$ and $\mathrm{X}$ species (with the exception of fully O-terminated $\mathrm{Ti}_{2} \mathrm{C}$, which becomes semiconducting). Assuming the average carrier relaxation time is insensitive to surface composition, this suggests that the electrical conductivity is only weakly affected by functionalization.

Conversely, the DOS at the Fermi level increases concomitantly with the number of layers (Figure S6). Furthermore, for $\mathrm{Nb}$-based systems the Fermi level is located at a higher DOS region than for any of the other calculated MXenes as a result of the higher number of valence electrons. Because the metallic conductivity of these MXenes is carried via the transition metal d-band states at Fermi level and the Fermi level remains within the d-band for most accessible surface compositions, the conductivity is weakly affected by the composition of the adsorbate layer.

In conclusion, we have systematically studied surface functionalization of six 2D MXenes $\mathrm{M}_{n+1} \mathrm{X}_{n}$ by $-\mathrm{O},-\mathrm{F}$, and $-\mathrm{OH}$. We explored the chemical space of MXenes considering different metallic species $(\mathrm{M}=\mathrm{Ti}, \mathrm{Nb})$, a variation of $\mathrm{X}$ species $(\mathrm{X}=\mathrm{C}, \mathrm{N})$, and variation in the number of atomic layers $(n=$ $2,3,4)$. Using a multiscale computational scheme, we calculated the distribution of functional groups and their 


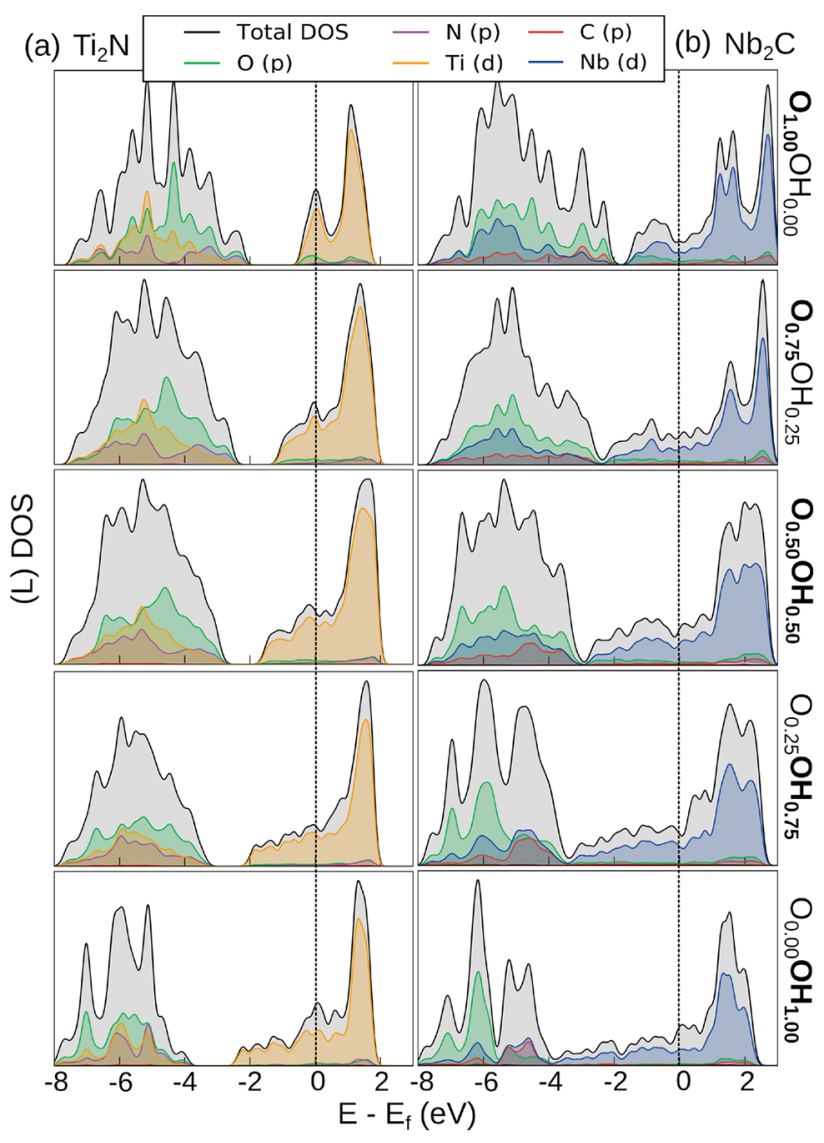

Figure 6. Atom-projected density of states for (a) $\mathrm{Ti}_{2} \mathrm{~N}$ and (b) $\mathrm{Nb}_{2} \mathrm{C}$ SQoSs with different $\mathrm{O}$ and $\mathrm{OH}$ composition. The top panel corresponds to the fully O-terminated surface, and the $\mathrm{OH}$ content gradually increases toward the bottom panel. The vertical dashed lines indicate the Fermi level position.

mixing energies. The surface functionalization of different MXenes exhibits similar distributions and mixing energies, which we propose are governed by interactions between $-\mathrm{O}$, $-\mathrm{F}$, and $-\mathrm{OH}$ and the geometry of the triangular lattice rather than the chemical nature of the $\mathrm{M}$ and $\mathrm{X}$ species or the number of atomic layers $(n)$. To simulate realistic synthesis conditions, Gibbs free energy of formation diagrams for different compositions of functional groups depending on $\mathrm{pH}$ and the potential were constructed. The Gibbs free energy of formation indicates a prevalence of $\mathrm{O}$ functionalization, regardless of $\mathrm{M}$, $\mathrm{X}$, and $n$ variation, and suggests that functionalization of the surface is driven by external conditions and not the type or thickness of the MXene. Finally, the work function of the surface varies dramatically, and linearly, with functional group composition, whereas the DOS at the Fermi level is only weakly affected by the surface groups.

MXenes are a wide class of materials with various properties and structures, but for most MXenes the functional group distribution has not been studied experimentally. While we focused on only a few of the most common MXenes, the surface functionalization behavior can be different for MXenes with different structures and properties than those of the systems studied in this work. Nevertheless, we hope that our findings will also be helpful in understanding the structure and properties of other MXenes.

\section{ASSOCIATED CONTENT}

\section{(s) Supporting Information}

The Supporting Information is available free of charge at https://pubs.acs.org/doi/10.1021/acs.jpclett.0c03710.

Methodology and results (PDF)

\section{AUTHOR INFORMATION}

\section{Corresponding Author}

Hannu-Pekka Komsa - Department of Applied Physics, Aalto University, 00076 Aalto, Finland; Microelectronics Research Unit, University of Oulu, $90014 \mathrm{Oulu}$, Finland; (i) orcid.org/0000-0002-0970-0957; Email: hannupekka.komsa@oulu.fi

\section{Authors}

Rina Ibragimova - Department of Applied Physics, Aalto University, 00076 Aalto, Finland; (1) orcid.org/0000-00015773-3457

Paul Erhart - Department of Physics, Chalmers University of Technology, S-412 96 Gothenburg, Sweden; 이이.org/ 0000-0002-2516-6061

Patrick Rinke - Department of Applied Physics, Aalto University, 00076 Aalto, Finland; 이이.org/0000-00031898-723X

Complete contact information is available at:

https://pubs.acs.org/10.1021/acs.jpclett.0c03710

\section{Notes}

The authors declare no competing financial interest.

\section{ACKNOWLEDGMENTS}

We acknowledge funding from the Academy of Finland under Project No. 311058. We gratefully acknowledge CSC-IT Center for Science, Finland, and the Aalto Science-IT project for generous computational resources. We also thank HPCEUROPA3 (INFRAIA-2016-1-730897) and the EC Research Innovation Action under the H2020 Programme. In particular, we acknowledge the computer resources and technical support provided by the Swedish National Infrastructure for Computing (SNIC) at PDC partially funded by the Swedish Research Council through Grant Agreement No. 2018-05973.

\section{REFERENCES}

(1) Anasori, B.; Lukatskaya, M. R.; Gogotsi, Y. 2D Metal Carbides and Nitrides (MXenes) for Energy Storage. Nat. Rev. Mater. 2017, 2, 16098.

(2) Gogotsi, Y.; Anasori, B. The Rise of MXenes. ACS Nano 2019, 13, 8491-8494.

(3) Mashtalir, O.; Naguib, M.; Mochalin, V. N.; Dall'Agnese, Y.; Heon, M.; Barsoum, M. W.; Gogotsi, Y. Intercalation and delamination of layered carbides and carbonitrides. Nat. Commun. 2013, 4, 1716.

(4) Verger, L.; Xu, C.; Natu, V.; Cheng, H.-M.; Ren, W.; Barsoum, M. W. Overview of the synthesis of MXenes and other ultrathin 2D transition metal carbides and nitrides. Curr. Opin. Solid State Mater. Sci. 2019, 23, 149-163.

(5) Kim, H.; Anasori, B.; Gogotsi, Y.; Alshareef, H. N. Thermoelectric Properties of Two-Dimensional Molybdenum-Based MXenes. Chem. Mater. 2017, 29, 6472-6479.

(6) Tao, Q.; Dahlqvist, M.; Lu, J.; Kota, S.; Meshkian, R.; Halim, J.; Palisaitis, J.; Hultman, L.; Barsoum, M. W.; Persson, P. O. Å.; et al. Two-dimensional Mo1.33C MXene with divacancy ordering prepared from parent 3D laminate with in-plane chemical ordering. Nat. Commun. 2017, 8, 14949. 
(7) Halim, J.; Cook, K. M.; Naguib, M.; Eklund, P.; Gogotsi, Y.; Rosen, J.; Barsoum, M. W. X-ray photoelectron spectroscopy of select multi-layered transition metal carbides (MXenes). Appl. Surf. Sci. 2016, 362, 406-417.

(8) Xin, Y.; Yu, Y.-X. Possibility of bare and functionalized niobium carbide MXenes for electrode materials of supercapacitors and field emitters. Mater. Des. 2017, 130, 512-520.

(9) Deysher, G.; Shuck, C. E.; Hantanasirisakul, K.; Frey, N. C.; Foucher, A. C.; Maleski, K.; Sarycheva, A.; Shenoy, V. B.; Stach, E. A.; Anasori, B.; et al. Synthesis of Mo4VAlC4MAX Phase and TwoDimensional Mo4VC4MXene with Five Atomic Layers of Transition Metals. ACS Nano 2020, 14, 204-217.

(10) Ghidiu, M.; Lukatskaya, M. R.; Zhao, M.-Q.; Gogotsi, Y.; Barsoum, M. W. Conductive Two-Dimensional Titanium Carbide 'Clay' with High Volumetric Capacitance. Nature 2014, 516, 78-81. (11) Zhang, C. J.; Anasori, B.; Seral-Ascaso, A.; Park, S.-H.; McEvoy, N.; Shmeliov, A.; Duesberg, G. S.; Coleman, J. N.; Gogotsi, Y.; Nicolosi, V. Transparent, Flexible, and Conductive 2D Titanium Carbide (MXene) Films with High Volumetric Capacitance. Adv. Mater. 2017, 29, 1702678.

(12) Cao, W.-T.; Chen, F.-F.; Zhu, Y.-J.; Zhang, Y.-G.; Jiang, Y.-Y.; Ma, M.-G.; Chen, F. Binary Strengthening and Toughening of MXene/Cellulose Nanofiber Composite Paper with Nacre-Inspired Structure and Superior Electromagnetic Interference Shielding Properties. ACS Nano 2018, 12, 4583-4593.

(13) Hantanasirisakul, K.; Zhao, M.-Q.; Urbankowski, P.; Halim, J.; Anasori, B.; Kota, S.; Ren, C. E.; Barsoum, M. W.; Gogotsi, Y. Fabrication of $\mathrm{Ti}_{3} \mathrm{C}_{2} \mathrm{~T}_{x}$ MXene Transparent Thin Films with Tunable Optoelectronic Properties. Adv. Electron. Mater. 2016, 2, 1600050.

(14) Lipatov, A.; Lu, H.; Alhabeb, M.; Anasori, B.; Gruverman, A.; Gogotsi, Y.; Sinitskii, A. Elastic properties of $2 \mathrm{D} \mathrm{Ti}_{3} \mathrm{C}_{2} \mathrm{~T}_{x}$ MXene monolayers and bilayers. Science Advances 2018, 4, eaat0491.

(15) Khaledialidusti, R.; Anasori, B.; Barnoush, A. Temperaturedependent mechanical properties of $\operatorname{Tin}+1 \mathrm{CnO} 2(\mathrm{n}=1,2)$ MXene monolayers: a first-principles study. Phys. Chem. Chem. Phys. 2020, 22, 3414-3424.

(16) Handoko, A. D.; Chen, H.; Lum, Y.; Zhang, Q.; Anasori, B.; Seh, Z. W. Two-Dimensional Titanium and Molybdenum Carbide MXenes as Electrocatalysts for CO2 Reduction. iScience 2020, 23, 101181.

(17) Khaledialidusti, R.; Mishra, A. K.; Barnoush, A. Atomic defects in monolayer ordered double transition metal carbide (Mo2TiC2Tx) MXene and CO2 adsorption. J. Mater. Chem. C 2020, 8, 4771-4779.

(18) Xie, Y.; Naguib, M.; Mochalin, V. N.; Barsoum, M. W.; Gogotsi, Y.; Yu, X.; Nam, K.-W.; Yang, X.-Q.; Kolesnikov, A. I.; Kent, P. R. C. Role of Surface Structure on Li-Ion Energy Storage Capacity of TwoDimensional Transition-Metal Carbides. J. Am. Chem. Soc. 2014, 136, 6385-6394.

(19) Naguib, M.; Kurtoglu, M.; Presser, V.; Lu, J.; Niu, J.; Heon, M.; Hultman, L.; Gogotsi, Y.; Barsoum, M. W. Two-Dimensional Nanocrystals Produced by Exfoliation of $\mathrm{Ti}_{3} \mathrm{AlC}_{2}$. Adv. Mater. 2011, 23, 4248-4253.

(20) Mashtalir, O.; Naguib, M.; Dyatkin, B.; Gogotsi, Y.; Barsoum, M. W. Kinetics of Aluminum Extraction from $\mathrm{Ti}_{3} \mathrm{AlC}_{2}$ in Hydrofluoric Acid. Mater. Chem. Phys. 2013, 139, 147-152.

(21) Shi, C.; Beidaghi, M.; Naguib, M.; Mashtalir, O.; Gogotsi, Y.; Billinge, S. J. L. Structure of Nanocrystalline $\mathrm{Ti}_{3} \mathrm{C}_{2}$ MXene Using Atomic Pair Distribution Function. Phys. Rev. Lett. 2014, 112, 125501.

(22) Persson, I.; Näslund, L.-Å.; Halim, J.; Barsoum, M. W.; Darakchieva, V.; Palisaitis, J.; Rosen, J.; Persson, P. O. Å. On the Organization and Thermal Behavior of Functional Groups on $\mathrm{Ti}_{3} \mathrm{C}_{2}$ MXene Surfaces in Vacuum. 2D Mater. 2018, 5, 015002.

(23) Halim, J.; Cook, K. M.; Naguib, M.; Eklund, P.; Gogotsi, Y.;

Rosen, J.; Barsoum, M. W. X-Ray Photoelectron Spectroscopy of Select Multi-Layered Transition Metal Carbides (MXenes). Appl. Surf. Sci. 2016, 362, 406-417.

(24) Mariano, M.; Mashtalir, O.; Antonio, F. Q.; Ryu, W.-H.; Deng, B.; Xia, F.; Gogotsi, Y.; Taylor, A. D. Solution-Processed Titanium
Carbide MXene Films Examined as Highly Transparent Conductors. Nanoscale 2016, 8, 16371-16378.

(25) Khazaei, M.; Ranjbar, A.; Arai, M.; Sasaki, T.; Yunoki, S. Electronic Properties and Applications of MXenes: A Theoretical Review. J. Mater. Chem. C 2017, 5 (10), 2488-2503.

(26) Chertopalov, S.; Mochalin, V. N. Environment-Sensitive Photoresponse of Spontaneously Partially Oxidized $\mathrm{Ti}_{3} \mathrm{C}_{2}$ MXene Thin Films. ACS Nano 2018, 12, 6109-6116.

(27) Hart, J. L.; Hantanasirisakul, K.; Lang, A. C.; Anasori, B.; Pinto, D.; Pivak, Y.; van Omme, J. T.; May, S. J.; Gogotsi, Y.; Taheri, M. L. Control of MXenes Electronic Properties Through Termination and Intercalation. Nat. Commun. 2019, 10, 522.

(28) Urbankowski, P.; Anasori, B.; Makaryan, T.; Er, D.; Kota, S.; Walsh, P. L.; Zhao, M.; Shenoy, V. B.; Barsoum, M. W.; Gogotsi, Y. Synthesis of two-dimensional titanium nitride $\mathrm{Ti} 4 \mathrm{~N} 3$ (MXene). Nanoscale 2016, 8, 11385-11391.

(29) Djire, A.; Bos, A.; Liu, J.; Zhang, H.; Miller, E. M.; Neale, N. R. Pseudocapacitive Storage in Nanolayered Ti 2 NT x MXene Using Mg-Ion Electrolyte. ACS Applied Nano Materials 2019, 2, 2785-2795.

(30) Djire, A.; Zhang, H.; Liu, J.; Miller, E. M.; Neale, N. R. Electrocatalytic and Optoelectronic Characteristics of the TwoDimensional Titanium Nitride Ti $4 \mathrm{~N} 3 \mathrm{~T}$ x MXene. ACS Appl. Mater. Interfaces 2019, 11, 11812-11823.

(31) Naguib, M.; Halim, J.; Lu, J.; Cook, K. M.; Hultman, L.; Gogotsi, Y.; Barsoum, M. W. New Two-Dimensional Niobium and Vanadium Carbides as Promising Materials for Li-Ion Batteries. J. Am. Chem. Soc. 2013, 135, 15966-15969.

(32) Palisaitis, J.; Persson, I.; Halim, J.; Rosen, J.; Persson, P. O. Å. On the Structural Stability of MXene and the Role of Transition Metal Adatoms. Nanoscale 2018, 10, 10850-10855.

(33) Halim, J.; Persson, I.; Moon, E. J.; Kühne, P.; Darakchieva, V.; Persson, P. O. Å.; Eklund, P.; Rosen, J.; Barsoum, M. W. Electronic and optical characterization of $2 \mathrm{D}$ Ti2C and Nb2C (MXene) thin films. J. Phys.: Condens. Matter 2019, 31, 165301.

(34) Ghidiu, M.; Naguib, M.; Shi, C.; Mashtalir, O.; Pan, L. M.; Zhang, B.; Yang, J.; Gogotsi, Y.; Billinge, S. J. L.; Barsoum, M. W. Synthesis and characterization of two-dimensional Nb4C3 (MXene). Chem. Commun. 2014, 50, 9517-9520.

(35) Soundiraraju, B.; George, B. K. Two-Dimensional Titanium Nitride (Ti 2 N) MXene: Synthesis, Characterization, and Potential Application as Surface-Enhanced Raman Scattering Substrate. ACS Nano 2017, 11, 8892-8900.

(36) Hope, M. A.; Forse, A. C.; Griffith, K. J.; Lukatskaya, M. R.; Ghidiu, M.; Gogotsi, Y.; Grey, C. P. NMR Reveals the Surface Functionalisation of $\mathrm{Ti}_{3} \mathrm{C}_{2}$ MXene. Phys. Chem. Chem. Phys. 2016, 18, 5099-5102.

(37) Sang, X.; Xie, Y.; Lin, M.-W.; Alhabeb, M.; Van Aken, K. L.; Gogotsi, Y.; Kent, P. R. C.; Xiao, K.; Unocic, R. R. Atomic Defects in Monolayer Titanium Carbide $\left(\mathrm{Ti}_{3} \mathrm{C}_{2} \mathrm{~T}_{x}\right)$ MXene. ACS Nano 2016, 10, 9193-9200.

(38) Khazaei, M.; Arai, M.; Sasaki, T.; Ranjbar, A.; Liang, Y.; Yunoki, S. OH-Terminated Two-Dimensional Transition Metal Carbides and Nitrides as Ultralow Work Function Materials. Phys. Rev. B: Condens. Matter Mater. Phys. 2015, 92, 075411.

(39) Khazaei, M.; Arai, M.; Sasaki, T.; Estili, M.; Sakka, Y. Trends in electronic structures and structural properties of MAX phases: a firstprinciples study on M2AlC ( $\mathrm{M}=\mathrm{Sc}, \mathrm{Ti}, \mathrm{Cr}, \mathrm{Zr}, \mathrm{Nb}, \mathrm{Mo}, \mathrm{Hf}$, or $\mathrm{Ta})$, M2AlN, and hypothetical M2AlB phases. J. Phys.: Condens. Matter 2014, 26, 505503.

(40) Wang, D.; Gao, Y.; Liu, Y.; Jin, D.; Gogotsi, Y.; Meng, X.; Du, F.; Chen, G.; Wei, Y. First-Principles Calculations of Ti2N and Ti2NT2 $(\mathrm{T}=\mathrm{O}, \mathrm{F}, \mathrm{OH})$ Monolayers as Potential Anode Materials for Lithium-Ion Batteries and Beyond. J. Phys. Chem. C 2017, 121, 13025-13034.

(41) Xie, Y.; Kent, P. R. C. Hybrid Density Functional Study of Structural and Electronic Properties of Functionalized $\mathrm{Ti}_{n+1} X_{n}(X=\mathrm{C}$, N) Monolayers. Phys. Rev. B: Condens. Matter Mater. Phys. 2013, 87, 235441. 
(42) Yu, Y.-X. Prediction of Mobility, Enhanced Storage Capacity, and Volume Change during Sodiation on Interlayer-Expanded Functionalized $\mathrm{Ti}_{3} \mathrm{C}_{2}$ MXene Anode Materials for Sodium-Ion Batteries. J. Phys. Chem. C 2016, 120, 5288-5296.

(43) Ashton, M.; Mathew, K.; Hennig, R. G.; Sinnott, S. B. Predicted Surface Composition and Thermodynamic Stability of MXenes in Solution. J. Phys. Chem. C 2016, 120, 3550-3556.

(44) Enyashin, A.; Ivanovskii, A. Atomic Structure, Comparative Stability and Electronic Properties of Hydroxylated $\mathrm{Ti}_{2} \mathrm{C}$ and $\mathrm{Ti}_{3} \mathrm{C}_{2}$ Nanotubes. Comput. Theor. Chem. 2012, 989, 27-32.

(45) Hu, T.; Hu, M.; Gao, B.; Li, W.; Wang, X. Screening Surface Structure of MXenes by High-Throughput Computation and Vibrational Spectroscopic Confirmation. J. Phys. Chem. C 2018, 122, 18501-18509.

(46) Mishra, A.; Srivastava, P.; Carreras, A.; Tanaka, I.; Mizuseki, H.; Lee, K.-R.; Singh, A. K. Atomistic Origin of Phase Stability in OxygenFunctionalized MXene: A Comparative Study. J. Phys. Chem. C 2017, 121, 18947-18953.

(47) Rajan, A. C.; Mishra, A.; Satsangi, S.; Vaish, R.; Mizuseki, H.; Lee, K.-R.; Singh, A. K. Machine-Learning-Assisted Accurate Band Gap Predictions of Functionalized MXene. Chem. Mater. 2018, 30, 4031.

(48) Zhang, H.; Yang, G.; Zuo, X.; Tang, H.; Yang, Q.; Li, G. Computational studies on the structural, electronic and optical properties of graphene-like MXenes (M2CT2, $\mathrm{M}=\mathrm{Ti}, \mathrm{Zr}, \mathrm{Hf}$; $\mathrm{T}=\mathrm{O}$, $\mathrm{F}, \mathrm{OH})$ and their potential applications as visible-light driven photocatalysts. J. Mater. Chem. A 2016, 4, 12913-12920.

(49) Kumar, H.; Frey, N. C.; Dong, L.; Anasori, B.; Gogotsi, Y.; Shenoy, V. B. Tunable Magnetism and Transport Properties in Nitride MXenes. ACS Nano 2017, 11, 7648-7655. PMID: 28558192.

(50) Berdiyorov, G. R. Optical properties of functionalized Ti3C2T2 $(\mathrm{T}=\mathrm{F}, \mathrm{O}, \mathrm{OH}) \mathrm{MXene:} \mathrm{First-principles} \mathrm{calculations.} \mathrm{AIP} \mathrm{Adv.} \mathrm{2016,}$ 6, 055105 .

(51) Berdiyorov, G. R.; Madjet, M. E.; Mahmoud, K. A. Ionic sieving through $\mathrm{Ti}_{3} \mathrm{C}_{2}(\mathrm{OH})_{2}$ MXene: First-principles calculations. Appl. Phys. Lett. 2016, 108, 113110 .

(52) Wang, D.; Li, F.; Lian, R.; Xu, J.; Kan, D.; Liu, Y.; Chen, G.; Gogotsi, Y.; Wei, Y. A General Atomic Surface Modification Strategy for Improving Anchoring and Electrocatalysis Behavior of Ti3C2T2MXene in Lithium-Sulfur Batteries. ACS Nano 2019, 13, 11078-11086.

(53) Champagne, A.; Shi, L.; Ouisse, T.; Hackens, B.; Charlier, J.-C. Electronic and vibrational properties of $\mathrm{V}_{2} \mathrm{C}$-based MXenes: From experiments to first-principles modeling. Phys. Rev. B: Condens. Matter Mater. Phys. 2018, 97, 115439.

(54) Srivastava, P.; Mishra, A.; Mizuseki, H.; Lee, K.-R.; Singh, A. K. Mechanistic Insight into the Chemical Exfoliation and Functionalization of $\mathrm{Ti}_{3} \mathrm{C}_{2}$ MXene. ACS Appl. Mater. Interfaces 2016, 8, 2425624264.

(55) Fu, Z. H.; Zhang, Q. F.; Legut, D.; Si, C.; Germann, T. C.; Lookman, T.; Du, S. Y.; Francisco, J. S.; Zhang, R. F. Stabilization and strengthening effects of functional groups in two-dimensional titanium carbide. Phys. Rev. B: Condens. Matter Mater. Phys. 2016, 94, 104103.

(56) Frey, N. C.; Bandyopadhyay, A.; Kumar, H.; Anasori, B.; Gogotsi, Y.; Shenoy, V. B. Surface-Engineered MXenes: Electric Field Control of Magnetism and Enhanced Magnetic Anisotropy. ACS Nano 2019, 13, 2831-2839.

(57) Caffrey, N. M. Effect of mixed surface terminations on the structural and electrochemical properties of two-dimensional Ti3C2T2 and V2CT2MXenes multilayers. Nanoscale 2018, 10, $13520-13530$.

(58) Schultz, T.; Frey, N. C.; Hantanasirisakul, K.; Park, S.; May, S. J.; Shenoy, V. B.; Gogotsi, Y.; Koch, N. Surface Termination Dependent Work Function and Electronic Properties of Ti3C2Tx MXene. Chem. Mater. 2019, 31, 6590-6597.
(59) Ibragimova, R.; Puska, M. J.; Komsa, H.-P. pH-Dependent Distribution of Functional Groups on Titanium-Based MXenes. ACS Nano 2019, 13, 9171-9181.

(60) Kresse, G.; Furthmüller, J. Efficient iterative schemes for $a b$ initio total-energy calculations using a plane-wave basis set. Phys. Rev. B: Condens. Matter Mater. Phys. 1996, 54, 11169-11186.

(61) Ångqvist, M.; Muñoz, W. A.; Rahm, J. M.; Fransson, E.; Durniak, C.; Rozyczko, P.; Rod, T. H.; Erhart, P. ICET - A Python Library for Constructing and Sampling Alloy Cluster Expansions. Advanced Theory and Simulations 2019, 2, 1900015.

(62) Tipping, M. E. Sparse Bayesian Learning and the Relevance Vector Machine. J. Mach. Learn. Res. 2001, 1, 211-244.

(63) See the Supporting Information.

(64) Zunger, A.; Wei, S.-H.; Ferreira, L. G.; Bernard, J. E. Special Quasirandom Structures. Phys. Rev. Lett. 1990, 65, 353-356.

(65) Liu, J.; Fernández-Serra, M. V.; Allen, P. B. Special Quasiordered Structures: Role of Short-Range Order in the Semiconductor Alloy $(\mathrm{GaN})_{1-x}(\mathrm{ZnO})_{x}$. Phys. Rev. B: Condens. Matter Mater. Phys. 2016, 93, 054207.

(66) Moessner, R.; Ramirez, A. P. Geometrical frustration. 2006; http://physicstoday.scitation.org/doi/10.1063/1.2186278.

(67) Henkelman, G.; Arnaldsson, A.; Jónsson, H. A fast and robust algorithm for Bader decomposition of charge density. Comput. Mater. Sci. 2006, 36, 354-360.

(68) Yang, S.; Zhang, P.; Wang, F.; Ricciardulli, A. G.; Lohe, M. R.; Blom, P. W. M.; Feng, X. Fluoride-Free Synthesis of TwoDimensional Titanium Carbide (MXene) Using A Binary Aqueous System. Angew. Chem., Int. Ed. 2018, 57, 15491-15495.

(69) Karlsson, L. H.; Birch, J.; Halim, J.; Barsoum, M. W.; Persson, P. O. Å. Atomically Resolved Structural and Chemical Investigation of Single MXene Sheets. Nano Lett. 2015, 15, 4955-4960.

(70) Wang, H.-W.; Naguib, M.; Page, K.; Wesolowski, D. J.; Gogotsi, Y. Resolving the Structure of $\mathrm{Ti}_{3} \mathrm{C}_{2} \mathrm{Ti}_{x}$ MXenes through Multilevel Structural Modeling of the Atomic Pair Distribution Function. Chem. Mater. 2016, 28, 349-359.

(71) Anayee, M.; Kurra, N.; Alhabeb, M.; Seredych, M.; Hedhili, M. N.; Emwas, A.-H.; Alshareef, H. N.; Anasori, B.; Gogotsi, Y. Role of acid mixtures etching on the surface chemistry and sodium ion storage in Ti3C2Tx MXene. Chem. Commun. 2020, 56, 6090-6093.

(72) Griffith, K. J.; Hope, M. A.; Reeves, P. J.; Anayee, M.; Gogotsi, Y.; Grey, C. P. Bulk and Surface Chemistry of the Niobium MAX and MXene Phases from Multinuclear Solid-State NMR Spectroscopy. J. Am. Chem. Soc. 2020, 142, 18924-18935.

(73) Agresti, A.; Pazniak, A.; Pescetelli, S.; Di Vito, A.; Rossi, D.; Pecchia, A.; Auf der Maur, M.; Liedl, A.; Larciprete, R.; Kuznetsov, D. V.; et al. Titanium-carbide MXenes for work function and interface engineering in perovskite solar cells. Nat. Mater. 2019, 18, 12281234. 